\section{A RANDOMIZED STUDY OF THE INFLUENCE OF PERFUSION TECHNIQUE AND PH MANAGEMENT STRATEGY IN 316 PATIENTS UNDERGOING CORONARY ARTERY BYPASS SURGERY}

\section{Mortality and cardiovascular morbidity}

The impact of perfusion technique and mode of $\mathrm{pH}$ management during cardiopulmonary bypass has not been well characterized with respect to postoperative cardiovascular outcome. Methods: This double-blind, randomized study comparing outcomes after alpha-stat or $\mathrm{pH}$-stat management and pulsatile or nonpulsatile perfusion during moderate hypothermic cardiopulmonary bypass was undertaken in $\mathbf{3 1 6}$ patients undergoing coronary artery bypass operations. Results: Cardiovascular morbidity and mortality were not affected by $\mathrm{pH}$ management, and the incidence of stroke (2.5\%) did not differ between groups. Overall in-hospital mortality was $2.8 \%$, eight of the nine deaths occurring in the nonpulsatile group $(5.1 \%$ versus $0.6 \% ; p=0.018)$. The incidence of myocardial infarction was $5.7 \%$ in the nonpulsatile group and $0.6 \%$ in the pulsatile group $(p=0.010)$, and use of intraaortic balloon pulsation was significantly more common in the nonpulsatile group ( $7.0 \%$ versus $1.9 \% ; p=0.029$ ). The overall percentage of patients having major complications was also significantly higher in the nonpulsatile group (15.2\% versus $5.7 \% ; p=0.006$ ). Duration of cardiopulmonary bypass, age, and use of nonpulsatile perfusion all correlated significantly with adverse outcome. Conclusions: Use of pulsatile perfusion during cardiopulmonary bypass was associated with decreased incidences of myocardial infarction, death, and major complications. (J THORAC CARDIOvaSC SURG 1995;110:340-8)

J. M. Murkin, MD, FRCPC, ${ }^{\text {a }}$ J. S. Martzke, PhD, RPsych, ${ }^{\mathrm{b}}$

A. M. Buchan, MD, FRCPC, ${ }^{\mathrm{c}} \mathrm{C}$. Bentley, RN, ${ }^{\mathrm{a}}$ and C. J. Wong, MSc, ${ }^{\mathrm{d}}$

London and Ottawa, Ontario, and Vancouver, British Columbia, Canada $0^{\prime}$ ptimal perfusion characteristics during cardiopulmonary bypass (CPB) remain controversial. ${ }^{1,2}$ The use of pulsatile perfusion has been variously demonstrated to improve myocardial perfusion, ${ }^{3,4}$ oxygenation, ${ }^{4-6}$ compliance, and indices of contractility, ${ }^{7,8}$ as well as to lower plasma catechol-

From the Department of Anaesthesia, University Hospital, University of Western Ontario, ${ }^{a}$ and Clinical Trials Resources Group, Robarts Research Institute, ${ }^{\mathrm{d}}$ London, Ontario; the Department of Psychology, Vancouver Hospital and Health Sciences Centre, ${ }^{b}$ Vancouver, British Columbia; and the Department of Neurology, Civic Hospital, University of Ottawa, ${ }^{\mathrm{c}}$ Ottawa, Ontario, Canada.

Supported by grant A1498 from the Heart and Stroke Foundation of Ontario.

Presented in part at the Sixty-seventh Congress of the International Anesthesia Research Society, San Diego, Calif., March 1993.

Received for publication Aug. 2, 1994.

Accepted for publication Dec. 22, 1994.

Address for reprints: John M. Murkin, MD, FRCPC, Department of Anaesthesia, University Hospital, 339 Windermere Rd., London, Ontario, Canada N6A 5A5.

Copyright (C 1995 by Mosby-Year Book, Inc.

$0022-5223 / 95 \$ 3.00+0 \quad \mathbf{1 2 / 1 / 6 3 3 4 0}$ amine levels, ${ }^{9,10}$ renin activity, ${ }^{11}$ angiotensin, aldosterone, ${ }^{12}$ and lactate ${ }^{13}$ levels, and to provide better preservation of pituitary responsiveness. ${ }^{14,15}$

Many clinical studies have also demonstrated improved myocardial function and lower morbidity and mortality after pulsatile compared with nonpulsatile perfusion during CPB. ${ }^{9,}{ }^{16-19}$ In contradistinction, however, a seemingly equal number of clinical studies have been unable to detect benefit associated with pulsatile perfusion. ${ }^{20-26}$

Ideal $\mathrm{pH}$ management during moderate hypothermia for $\mathrm{CPB}$ has also been the subject of contention. Several studies have assessed the influence of $\mathrm{pH}$ management on brain and heart function, and most have demonstrated relative improvements with alpha-stat in comparison with $\mathrm{pH}$-stat management. ${ }^{27-29}$ Some animal studies have also shown improved myocardial performance and an elevated fibrillation threshold with alpha-stat management, ${ }^{27,28,30,31}$ whereas others have been unable to detect differences in the functional capacity of the myocardium whether the blood perfusate was controlled by means of either alpha-stat or $\mathrm{pH}$-stat management strategies. ${ }^{32}$ 
Prospective, randomized outcome studies assessing the differential impact of perfusion technique or $\mathrm{pH}$ management strategy on mortality and cardiovascular morbidity have been conducted. However, few have used sufficiently large sample sizes to demonstrate possible outcome benefit for such low base rate events as death and myocardial infarction (MI). In most cardiac centers, use of nonpulsatile perfusion during CPB continues to be routine, although use of alpha-stat $\mathrm{pH}$ management has been increasing over the past decade. We therefore undertook a prospective, randomized, double-blind study in 316 patients undergoing coronary artery bypass $(\mathrm{CAB})$ operations to assess differences in clinical outcome after use of pulsatile or nonpulsatile $\mathrm{CPB}$ and alpha-stat or $\mathrm{pH}$-stat $\mathrm{pH}$ management strategies.

\section{Methods}

This prospective, double-blind, clinical trial, randomized with respect to $\mathrm{pH}$ management and perfusion technique, was conducted as a part of a study assessing neurologic and cognitive outcomes in patients having cardiac operations. ${ }^{33}$

Study population. After institutional review board approval and written informed patient consent were obtained, 316 patients undergoing hypothermic CPB for $\mathrm{CAB}$ (excluding concomitant open chamber procedures) were enrolled in this study. To account for differences in surgical technique, randomization was stratified by surgeon (four surgeons) and patients were randomly assigned to undergo either pulsatile or nonpulsatile perfusion and alpha-stat or $\mathrm{pH}$-stat $\mathrm{pH}$ management.

Outcome measures. Each patient was assessed before and after the operation by a blinded research nurse, while an independent study technician obtained intraoperative hemodynamic data. Mortality and major complications, including MI, cerebrovascular accident (CVA), arrhythmia, use of an intraaortic balloon pump (IABP), and renal impairment, were recorded before the operation for each patient. Arrhythmia was defined as onset of atrial or ventricular arrhythmias necessitating cardioversion or institution of specific antiarrhythmic therapy in the postoperative period. CVA was diagnosed on the basis of clinical presentation and either confirmatory brain imaging or postmortem evidence of cerebral infarction. MI was diagnosed on the basis of development of new $\mathrm{Q}$ waves on the electrocardiogram and an elevation of creatinine kinase myocardial band levels greater than $10 \%$ of total creatine kinase. MI data do not include patients dying during the operation, in whom such data could not be obtained, although these latter patients were included in mortality statistics. IABP use was defined as successful insertion of the IABP. Renal impairment was defined as elevations of creatinine concentration $50 \%$ above the upper limit of laboratory reference normal values.

CPB. Routine monitoring, including radial and pulmonary artery cannulation, and high-dose opioid anesthesia, supplemented as necessary with volatile anesthetics, were used similarly in all groups. After sternotomy and heparinization, moderate systemic hypothermia (nasopharyngeal temperature $26^{\circ}$ to $28^{\circ} \mathrm{C}$ ) with a hollow-fiber membrane oxygenator (Cobe CML, Cobe Stockert Inc., Lakewood, Colo.; Terumo Capiox E, Terumo Corp., Tokyo, Japan) having a $40 \mu \mathrm{m}$ arterial line filter and nonocclusive roller pump, was used for CPB in all patients. Flows of 2.0 to $2.5 \mathrm{~L} \cdot \mathrm{min}^{-1} \cdot \mathrm{m}^{-2}$ were used. Crystalloid cardioplegia was used by two surgeons, the other two used a 4:1 blood/crystalloid cardioplegic mixture, and all surgeons used topical cooling with saline slush. Ventricular venting was either through the ascending aorta or the pulmonary vein. After completion of all distal coronary anastomoses, the crossclamp was released, rewarming commenced, and proximal graft anastomoses performed by means of side-clamping of the aorta.

In the pulsatile group a pump flow interrupter (Pulsatile Flow Controller II, Cobe Stockert Inc.), initially set at rate of $65 \mathrm{cps}$ with an ejection time of $65 \%$ of cycle time, was used from placement of the aortic crossclamp until commencement of ventricular ejection after rewarming. Analog displays of pulse pressure and mean arterial pressure were recorded continuously and analyzed specifically after 10,30 , and 60 minutes of hypothermic CPB, at commencement of rewarming, and after rewarming was completed (i.e., rectal temperature at or above $34^{\circ} \mathrm{C}$ ). Hemodynamic data during hypothermia are reported as the means of all specific time point values during stable hypothermia. Values for normothermia were based on those obtained after completion of rewarming.

Arterial blood gas analysis was performed with a Radiometer ABL2 analyzer (Radiometer Als, Copenhagen, Denmark). For alpha-stat management during CPB, arterial blood gas was measured at $37^{\circ} \mathrm{C}$ and carbon dioxide was adjusted to produce an arterial carbon dioxide tension of $40 \mathrm{~mm} \mathrm{Hg}$ and an arterial $\mathrm{pH}$ of 7.4. For pH-stat management, arterial blood gas was measured at $37^{\circ} \mathrm{C}$ and corrected to the patient's nasopharyngeal temperature with exogenous carbon dioxide adjusted to maintain a temperature-corrected arterial carbon dioxide tension of $40 \mathrm{~mm} \mathrm{Hg}$ and a temperature-corrected arterial $\mathrm{pH}$ of 7.4. During CPB, intermittent blood gas analyses, based on samples drawn at intervals corresponding to the specific time points for hemodynamic measurements, were used to maintain either temperature corrected $(\mathrm{pH}$-stat management) or non-temperature corrected (alpha-stat management) arterial $\mathrm{pH} 7.4$ and arterial carbon dioxide tension $40 \mathrm{~mm} \mathrm{Hg}$. Simultaneously with arterial blood gas sampling, blood was obtained for glucose and hemoglobin measurements.

Statistical analysis. Log-linear model analysis was first performed to ensure that no interaction existed between $\mathrm{pH}$ management, perfusion technique, and outcome events. Outcome events were compared between treatment groups by the $\chi^{2}$ test. Fisher's two-tailed exact test was used if the expected cell sizes were small. Demographic characteristics were assessed similarly for categoric variables. Two-way factorial analysis of variance was used to examine continuous variables and to confirm that $\mathrm{pH}$ management did not interact with perfusion tech- 
Table I. CAB group demographics (numbers of patients, or mean \pm standard deviation)

\begin{tabular}{|c|c|c|c|c|c|}
\hline & \multicolumn{2}{|c|}{ Alpha-stat } & \multicolumn{2}{|c|}{$p H$-stat } & \multirow[b]{2}{*}{$\begin{array}{l}C A B \text { total } \\
(n=316)\end{array}$} \\
\hline & $\begin{array}{l}\text { Pulsatile } \\
(n=79)\end{array}$ & $\begin{array}{c}\text { Nonpulsatile } \\
(n=79)\end{array}$ & $\begin{array}{l}\text { Pulsatile } \\
(n=79)\end{array}$ & $\begin{array}{c}\text { Nonpulsatile } \\
(n=79)\end{array}$ & \\
\hline Age $(y r)$ & $60.9 \pm 8.7$ & $61.2 \pm 7.8$ & $60.2 \pm 8.5$ & $61.4 \pm 8.4$ & $60.9 \pm 8.3$ \\
\hline Gender $(\mathrm{M} / \mathrm{F})$ & $66 / 13$ & $65 / 14$ & $70 / 9$ & $63 / 16$ & $264 / 52$ \\
\hline CVA/TIA & 8 & 11 & 9 & 4 & $32(10 \%)$ \\
\hline DM & 20 & 17 & 8 & 13 & $58(18 \%)$ \\
\hline $\mathrm{MI}<1 / 12$ & 9 & 9 & 9 & 6 & $33(10 \%)$ \\
\hline Prev. CAB & 4 & 9 & 8 & 7 & $28(9 \%)$ \\
\hline LVEF < $<0 \%$ & 23 & 23 & 29 & 22 & $97(31 \%)$ \\
\hline $\mathrm{LVEF}<35 \%$ & 5 & 6 & 4 & 2 & $17(5 \%)$ \\
\hline
\end{tabular}

CVA/TLA, History of cerebrovascular accident or transient ischemic attack; $D M$, diabetes mellitus; $M I<1 / 12$, myocardial infarction in previous month; Prev. $C A B$, previous coronary bypass surgery; $L V E F<50 \%, L V E F<35 \%$, patients with left ventricular ejection fraction less than $50 \%$ or $35 \%$.

Table II. Distribution and intraoperative characteristics by CAB group (numbers of patients, or mean \pm standard deviation)

\begin{tabular}{|c|c|c|c|c|c|}
\hline & \multicolumn{2}{|c|}{ Alpha-stat } & \multicolumn{2}{|c|}{$p H$-stat } & \multirow[b]{2}{*}{$\begin{array}{l}C A B \text { total } \\
(n=316)\end{array}$} \\
\hline & $\begin{array}{l}\text { Pulsatile } \\
(n=79)\end{array}$ & $\begin{array}{c}\text { Nonpulsatile } \\
(n=79)\end{array}$ & $\begin{array}{l}\text { Pulsatile } \\
(n=79)\end{array}$ & $\begin{array}{c}\text { Nonpulsatile } \\
(n=79)\end{array}$ & \\
\hline Surgeon 1 & 22 & 24 & 24 & 24 & 94 \\
\hline Surgeon 2 & 26 & 25 & 22 & 26 & 99 \\
\hline Surgeon 3 & 5 & 6 & 6 & 4 & 21 \\
\hline Surgeon 4 & 26 & 24 & 27 & 25 & 102 \\
\hline NPT $\left({ }^{\circ} \mathrm{C}\right)$ & $28.5 \pm 2.1$ & $28.5 \pm 1.2$ & $28.5 \pm 2.0$ & $28.2 \pm 1.2$ & $28.4 \pm 1.7$ \\
\hline $\mathrm{Hgb}(\mathrm{gm} / \mathrm{L})$ & $78.4 \pm 18.4$ & $78.9 \pm 11.5$ & $81.5 \pm 14.5$ & $78.4 \pm 12.3$ & $79.3 \pm 14$ \\
\hline Glu $(\mathrm{mmol} / \mathrm{dl})$ & $10.6 \pm 3.5$ & $11.3 \pm 3.0$ & $10.4 \pm 3.1$ & $10.4 \pm 3.0$ & $10.7 \pm 3.1$ \\
\hline $\mathrm{CAB}$ & $2.9 \pm 0.6$ & $2.9 \pm 0.8$ & $3.0 \pm 0.8$ & $3.0 \pm 0.8$ & $3.0 \pm 0.7$ \\
\hline $\mathrm{CAB}>4$ & 10 & 16 & 22 & 17 & $65(21 \%)$ \\
\hline AoXC (min) & $43.9 \pm 17.4$ & $44.1 \pm 18.1$ & $47.8 \pm 17.2$ & $46.9 \pm 15.5$ & $45.7 \pm 17$ \\
\hline CPB (min) & $92.1 \pm 29.1$ & $95.1 \pm 29.1$ & $98.5 \pm 36.7$ & $98.6 \pm 32.6$ & $96.1 \pm 32$ \\
\hline OR (min) & $271 \pm 48$ & $280 \pm 76$ & $279 \pm 59$ & $282 \pm 57$ & $278 \pm 61$ \\
\hline Hosp (days) & $13.4 \pm 10.8$ & $12.2 \pm 5.1$ & $14.8 \pm 24.8$ & $12.9 \pm 11.1$ & $13.3 \pm 15$ \\
\hline
\end{tabular}

Surgeon $N$, Number of patients in each group operated on by individual surgeon; $N P T$, mean nasopharyngeal temperature during hypothermic CPB; $H g b$, lowest mean hemoglobin concentration during hypothermic $\mathrm{CPB} ; \mathrm{Gl}$, highest mean glucose values during hypothermic $\mathrm{CPB} ; \mathrm{CAB}$, mean number of coronary bypass grafts; $C A B>4$, patients having four or more coronary bypass grafts; $A O X C$, aortic crossclamp time; $C P B$, duration of cardiopulmonary bypass; $O R$, duration of operation; Hosp, operation to discharge time with in-hospital deaths excluded.

nique. No adjustments were made for multiple comparisons. Logistic regression analysis was applied to examine potential risk factors for adverse outcomes.

\section{Results}

Characteristics of patients. Demographic and clinical characteristics of the 316 patients in the study are shown in Table I. Table II shows distribution of patients into study group according to surgeon and intraoperative and postoperative values. No significant differences were identified between groups in any parameters including demographics, CPB duration, ischemic time, ventricular function, or numbers of coronary vessels bypassed.
Alpha-stat versus pH-stat groups. For pH management groups, intended treatments during CPB were achieved such that there was a significant difference in arterial $\mathrm{pH}$ of $0.11 \pm 0.18 \mathrm{pH}$ units and of arterial carbon dioxide tension of $20.6 \pm 7.8 \mathrm{~mm}$ $\mathrm{Hg}$ between alpha-stat and $\mathrm{pH}$-stat groups during hypothermic CPB (Table III).

Pulsatile versus nonpulsatile groups. During hypothermia, mean arterial pressure was similar between the two groups. Pulsatile perfusion was associated with a significantly greater pulse pressure, averaging $14.8 \pm 6.7 \mathrm{~mm} \mathrm{Hg}$ higher during hypothermic CPB and $6.8 \pm 14 \mathrm{~mm} \mathrm{Hg}$ higher during normothermic CPB than in the nonpulsatile group (see Table III). During CPB there were no differ- 
Table III. Perfusion characteristics by CAB group (mean \pm standard deviation)

\begin{tabular}{|c|c|c|c|c|}
\hline \multirow[b]{2}{*}{$\begin{array}{l}C A B \text { total } \\
(n=316)\end{array}$} & \multicolumn{2}{|c|}{ Alpha-stat } & \multicolumn{2}{|c|}{$p H$-stat } \\
\hline & $\begin{array}{l}\text { Pulsatile } \\
(n=79)\end{array}$ & $\begin{array}{c}\text { Nonpulsatile } \\
(n=79)\end{array}$ & $\begin{array}{l}\text { Pulsatile } \\
(n=79)\end{array}$ & $\begin{array}{c}\text { Nonpulsatile } \\
\quad(n=79)\end{array}$ \\
\hline PP-C $(\mathrm{mm} \mathrm{Hg})$ & $16.9 \pm 6.1^{*}$ & $1.8 \pm 2.4$ & $15.5 \pm 6.8^{*}$ & $1.6 \pm 2.4$ \\
\hline PP-NT (mm Hg) & $11.1 \pm 9.9^{*}$ & $5.5 \pm 12.6$ & $12.0 \pm 9.3^{*}$ & $4.1 \pm 7.3$ \\
\hline MABP (mm Hg) & $57.9 \pm 12.3$ & $61.0 \pm 11.3$ & $57.2 \pm 10.1$ & $57.6 \pm 11.9$ \\
\hline pHat & $7.42 \pm 0.18 \div$ & $7.43 \pm 0.12 \ddagger$ & $7.54 \pm 0.13$ & $7.54 \pm 0.06$ \\
\hline $\mathrm{PaCO}_{2}(\mathrm{~mm} \mathrm{Hg}) \dagger$ & $38.1 \pm 4.1 \ddagger$ & $37.5 \pm 4.1 \div$ & $57.5 \pm 6.9$ & $59.3 \pm 6.4$ \\
\hline
\end{tabular}

$P P-C$, Mean pulse pressure during hypothermic $\mathrm{CPB} ; P P-N T$, pulse pressure during normothermic $\mathrm{CPB} ; M A B P$, lowest mean arterial blood pressure during hypothermic $\mathrm{CPB} ; \mathrm{pHa}$, arterial $\mathrm{pH} ; \mathrm{PaCO}_{2}$, arterial carbon dioxide tension.

${ }^{*} p<0.001$ versus nonpulsatile.

$\dagger$ Mean of all values as measured at $37^{\circ} \mathrm{C}$ during hypothermic $\mathrm{CPB}$.

$\ddagger p=0.001$ versus $\mathrm{pH}$-stat.

ences in urine output between pulsatile or nonpulsatile groups $(367 \pm 346 \mathrm{ml}$ versus $378 \pm 358 \mathrm{ml}$, respectively), consistent with what we had observed in a subset of 100 of these patients in whom fractional excretion of sodium and potassium, as well as renal failure index, did not differ between perfusion groups. $^{34}$

Surgical morbidity and mortality. Data on cardiovascular and other major complications were assessed and patients with major complications are listed individually in Table IV. There was no difference in cardiovascular outcomes related to $\mathrm{pH}$ management (e.g., mortality $3 / 158$ versus $6 / 158$; MI $3 / 158$ versus $7 / 158$; alpha-stat versus $\mathrm{pH}$-stat, respectively). A significant difference in cardiovascular outcomes was observed that strongly favored pulsatile perfusion, however. In the nonpulsatile group there were significantly higher rates of mortality $(8 / 158$ versus $1 / 158, p=0.018)$, MI $(9 / 158$ versus $1 / 158, p=0.010)$, and IABP use $(11 / 158$ versus $3 / 158, p=0.029)$ than in the pulsatile group. These factors contributed toward a decreased overall incidence of major complications in the pulsatile group (24/158 versus $9 / 158, p=0.006)$. The percentage of patients who died or had major complications, broken down by perfusion technique, is presented in Fig. 1. To assess the effect of patients with complications disproportionately influencing morbidity data, we undertook a repeat analysis of complications involving only surviving patients. A trend $(p=$ 0.062 ) for fewer MIs in the pulsatile group persisted ( $1 / 157$ versus $6 / 150$, respectively). Of the patients who died, three died during the operation of cardiac failure, three died within 14 days after the operation of MI with irreversible low output state, one of whom also had a CVA, two died within 5 days of a
CVA with irreversible brain injury, and one patient died 4 months after the operation of multisystem failure.

Cardiovascular risk factors. Univariate logistic regression was used to determine the relationship between the presence of adverse outcomes, defined as death, MI, arrhythmia, or IABP insertion, and potential risk factors, identified as insulin-dependent diabetes mellitus, MI within the previous month, gender, left ventricular ejection fraction less than 0.5 , left ventricular ejection fraction less than 0.35 , number of coronary arteries grafted, perfusion technique, $\mathrm{pH}$ management strategy, cardioplegia type (blood or crystalloid), cardioplegia volume, age, duration of crossclamping, and duration of CPB. Significant correlations were found for use of nonpulsatile perfusion $(p=0.0082)$, age $(p=$ $0.0211)$, and CPB duration $(p=0.0006)$. When examined multivariately, these factors remained significant risk factors $(p=0.0106, p=0.0223$, and $p=$ 0.0003 , respectively) for adverse outcome. The other factors listed did not correlate with adverse outcome. Although cardioplegia type did not correlate with adverse outcome, surgeons using crystalloid cardioplegia completed more $\mathrm{CAB}$ grafts $(3.1 \pm 0.8$ versus $2.8 \pm 0.6$, respectively; $p=0.001$ ) with shorter crossclamp times $(41.5 \pm 14.1$ minutes versus $59.3 \pm 13.3$ minutes, respectively; $p<0.001$ ) than those using blood cardioplegia.

\section{Discussion}

The current study demonstrated significantly lower incidences of mortality and cardiovascular morbidity in patients undergoing pulsatile CPB but no detectable influence of $\mathrm{pH}$ management strategy on these outcome variables. The overall incidences 
Table IV. Individual mortality and major morbidity for pulsatile versus nonpulsatile $C P B$

\begin{tabular}{|c|c|c|c|c|c|c|}
\hline Patient & Death & $M I$ & Arrhythmia & $C V A$ & $I A B P$ & Renal \\
\hline \multicolumn{7}{|c|}{ Nonpulsatile CPB $(n=158)$} \\
\hline 1 & & $\mathrm{x}$ & $\mathrm{X}$ & & & $\mathrm{x}$ \\
\hline 2 & & $\mathrm{x}$ & & & & \\
\hline 3 & & $\mathrm{x}$ & & & & \\
\hline 4 & & $\mathrm{x}$ & & & $\mathrm{x}$ & \\
\hline 5 & & $\mathrm{x}$ & $\mathrm{x}$ & & $\mathrm{X}$ & \\
\hline 6 & & $\mathrm{x}$ & & & $\mathrm{x}$ & $\mathrm{x}$ \\
\hline 7 & $\mathrm{x}$ & $\mathrm{x}$ & & & $\mathrm{X}$ & \\
\hline 8 & $\mathrm{X}$ & $\mathrm{x}$ & & & $\mathrm{x}$ & $\mathrm{x}$ \\
\hline 9 & $\mathrm{x}$ & $\mathrm{x}$ & $\mathrm{x}$ & $\mathrm{x}$ & $\mathrm{x}$ & \\
\hline 10 & $\mathrm{x}$ & & & $\mathrm{x}$ & & \\
\hline 11 & $\mathrm{x}$ & & & & $\mathrm{x}$ & \\
\hline 12 & $\mathrm{x}$ & & & & $\mathrm{X}$ & \\
\hline 13 & $\mathrm{x}$ & & & $\mathrm{x}$ & & \\
\hline 14 & $\mathrm{x}$ & & & & $\mathrm{x}$ & \\
\hline 15 & & & & $\mathrm{x}$ & & \\
\hline 16 & & & & & & \\
\hline 17 & & & $\mathrm{x}$ & & & \\
\hline 18 & & & $\mathrm{x}$ & & & \\
\hline 19 & & & $\mathrm{x}$ & & & \\
\hline 20 & & & $\mathrm{x}$ & & & \\
\hline 21 & & & $\mathrm{x}$ & & & \\
\hline 22 & & & $\mathrm{x}$ & & & \\
\hline 23 & & & & & $\mathrm{x}$ & $\mathrm{x}$ \\
\hline 24 & & & & & $\mathrm{X}$ & \\
\hline \multicolumn{7}{|c|}{ Pulsatile CPB $(n=158)$} \\
\hline 1 & & & & $\mathrm{x}$ & $\mathrm{x}$ & \\
\hline 2 & & & & $\mathrm{x}$ & & \\
\hline 3 & & & & $\mathrm{x}$ & & \\
\hline 4 & & & & $\mathrm{x}$ & $\mathrm{x}$ & \\
\hline 5 & & $\mathrm{x}$ & $\mathrm{x}$ & & & \\
\hline 6 & & & $\mathrm{x}$ & & $\mathrm{x}$ & $\mathrm{X}$ \\
\hline 7 & & & & & & \\
\hline 8 & & & $\mathrm{x}$ & & & \\
\hline 9 & $\mathrm{x}$ & & $\mathrm{X}$ & & & \\
\hline$p=0.006^{*}$ & $p=0.018$ & $p=0.010$ & $p=0.157$ & $p=1.0$ & $p=0.029$ & $p=0.371$ \\
\hline
\end{tabular}

The incidence of death, myocardial infarction $(M I)$, postoperative arrhythmia necessitating treatment, cerebrovascular accident $(C V A)$, use of intraaortic balloon pump ( $L A B P$ ), and renal insufficiency for those patients undergoing pulsatile versus nonpulsatile perfusion during cardiopulmonary bypass ( $C P B$ ). The $p$ values comparing incidences of complications between the two groups are along the bottom of the table.

*This value refers to the relative incidences of any complications in the two groups.

of MI (3.2\%), IABP use (4.4\%), CVA $(2.5 \%)$, and mortality $(2.8 \%)$ reported in the current study are consistent with results reported in the literature. In a recent survey of 1513 patients undergoing $\mathrm{CAB}$, MI occurred in $5.5 \%, 4.7 \%$ required IABP, CVA occurred in $2.8 \%$, and overall mortality rate was $3.1 \% .^{35}$

pH management. Two divergent strategies for $\mathrm{pH}$ management have generally been used clinically: (1) $\mathrm{pH}$-stat-addition of exogenous carbon dioxide to the oxygenator to achieve a temperature-corrected arterial $\mathrm{pH}$ of 7.4 and an arterial carbon dioxide tension of $40 \mathrm{~mm} \mathrm{Hg}$; (2) alpha-stat- during which total carbon dioxide is kept constant and $\mathrm{pH}$ and arterial carbon dioxide tension vary with body temperature. ${ }^{29}$

In the current study, we did not find any influence of mode of $\mathrm{pH}$ management on cardiovascular morbidity or mortality. This observation likely reflects both the relatively insensitive clinical end points used (e.g., MI and LABP use) and, more fundamentally, the fact that the heart is not perfused and is effectively excluded from the systemic circulation (and thus largely uninfluenced by mode of $\mathrm{pH}$ management) during hypothermia by virtue of the aortic crossclamp. Rewarming, and thus conver- 


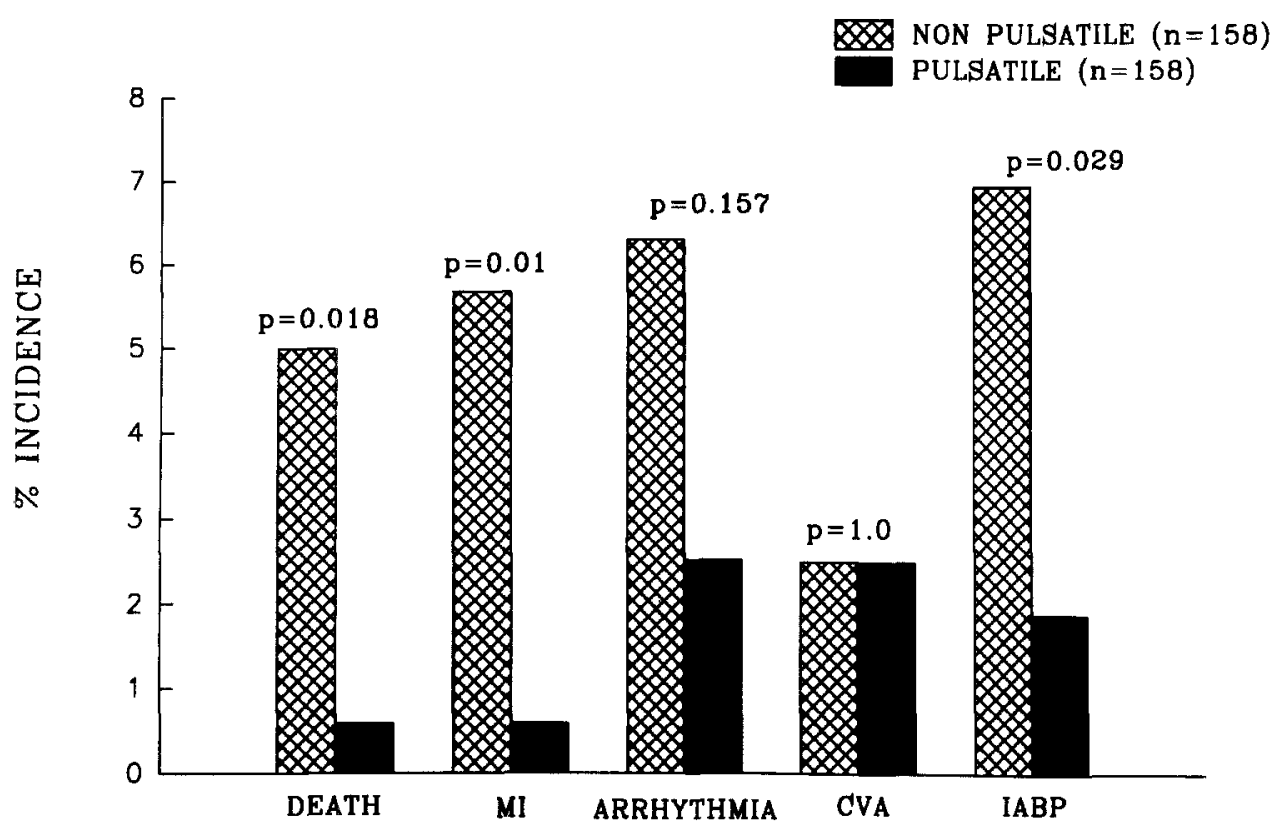

Fig. 1. The incidence of death, MI, postoperative arrhythmia necessitating treatment, CVA, and use of IABP for those patients undergoing pulsatile versus nonpulsatile perfusion during CPB.

gence of both alpha-stat and pH-stat strategies, generally commences during performance of the last of the distal coronary anastomoses, while the heart is still isolated from systemic perfusion.

Pulsatile perfusion. The current study documented markedly lower mortality in patients undergoing pulsatile CPB. Although nonfatal adverse outcomes (e.g., MI, IABP) and mortality overlapped, analysis of data from surviving patients still demonstrated a trend for a higher incidence of MI in the nonpulsatile group (6/150 versus $1 / 157)$. Reasons for these differences in outcome remain speculative. They are unlikely to reflect differences in surgical technique, because stratification by surgeon ensured that the number of patients in both pulsatile and nonpulsatile groups was balanced between surgeons. Assignment into pulsatile or nonpulsatile groups was also undertaken in a blinded fashion, and there was no subsequent crossover during the operations. Disproportionate weighting of patients at higher risk into one group or the other is thus unlikely, although no attempt was made preoperatively to stratify patients into treatment groups according to cardiovascular or other risk factors. Review of patient characteristics (see Tables I and II) confirms the randomization process and does not reveal any significant differences in preoperative risk factors.

To date only two other large-scale studies assessing cardiovascular outcomes after pulsatile or nonpulsatile CPB have been presented, and they have similarly reported salutary effects of pulsatile perfusion. Significantly decreased mortality rates with pulsatile perfusion were reported by Taylor and associates $^{18}$ in a series of 350 patients with cardiac disease randomized to pulsatile or nonpulsatile perfusion; Taylor's group used a roller-pump system similar to the one we employed. In that series significantly lower requirements for postoperative circulatory support modalities were demonstrated, and mortality from low-output cardiogenic shock was significantly decreased from $6.3 \%$ to $1.1 \%$. More recently, Minami and coworkers ${ }^{19}$ reported that in a retrospective comparison of 175 patients undergoing CPB for greater than 120 minutes, pulsatile perfusion decreased the incidence of cardiovascular morbidity, although overall mortality was not affected.

The mechanism responsible for the decreased incidence of cardiovascular complications remains speculative. However, it is possible that during the early reperfusion phase reductions in neurohumoral 
stress responses and improvements in myocardial contractility and subendocardial blood flow are contributory. ${ }^{3,4,7-10}$

In fibrillating hearts, increased myocardial oxygen and lactate extraction, improved subendocardial blood flow, ${ }^{3,4,36-38}$ and increased diastolic compliance $^{4}$ have been observed with pulsatile perfusion. Clinical studies also demonstrated increased ejection fractions, lower incidences of MI, and increased coronary graft blood flow. ${ }^{16,17,39}$ In the presence of acute coronary stenoses, pulsatile perfusion is associated with higher oxygen tension, lower tissue carbon dioxide tension, and greater subendocardial blood flow. ${ }^{5,} 38$ A recent study of dogs with coronary artery ligation and profound heart failure has confirmed increased coronary blood flow and an improved ratio of diastolic time index/tension time index with pulsatile as compared with nonpulsatile perfusion for left ventricular bypass. ${ }^{40}$ Lower levels of thromboxane and increased concentrations of prostacyclin, changes favoring coronary vasodilatation and augmented myocardial blood flow, have also been demonstrated with pulsatile perfusion. ${ }^{41}$

However, other studies have been unable to demonstrate any significant influence of perfusion technique. ${ }^{21-26}$ Overall, benefit does appear to be more likely at lower rather than higher perfusion flow rates, ${ }^{2}$ in fibrillating rather than beating hearts, $3,4,6$ and in the presence of global ischemia, ${ }^{8}$ ventricular hypertrophy, ${ }^{7}$ and acute ${ }^{5}$ rather than chronic ${ }^{42}$ ischemia.

Whether any of these experimental conditions are directly comparable to the clinical situation encountered during $\mathrm{CAB}$ operations, given that the heart is isolated and nonperfused for over half the duration of $\mathrm{CPB}$, is unclear. It is apparent that pulsatile perfusion can significantly increase subendocardial myocardial perfusion during ventricular fibrillation, particularly in the presence of coronary stenoses. It can also enhance subsequent loaddependent performance. In clinical practice the heart is often nonbeating or fibrillating for a variable period after removal of the aortic crossclamp, during which time the proximal graft anastomoses are being made. During this critical postischemic reperfusion phase, it may be that improved subendocardial perfusion, in conjunction with increased prostacyclin and decreased catecholamine levels, may be factors in the im- proved clinical cardiovascular outcomes demonstrated with pulsatile flow.

We are indebted for the support and cooperation of cardiac surgeons G. M. Guiraudon, F. N. McKenzie, A. M. Menkis, and R. L. Novick, perfusionists A. Cleland, M. Henderson, R. Mayer and J. MacDonald, and anesthesia research technician P. Lok. The assistance of D. A. Sim, D. Sharma, P. Campbell, and D. Giles is also acknowledged.

\section{REFERENCES}

1. Hickey PR, Buckley MT, Philbin DM. Pulsatile and nonpulsatile cardiopulmonary bypass: review of a counterproductive controversy. Ann Thorac Surg 1983;36:720-7.

2. Bartlett RH. Nonpulsatile flow-a noncontroversy. $\mathbf{J}$ Thorac Cardiovasc Surg [Letter] 1994;107:644-5.

3. Steed DL, Follette DM, Foglia R, Maloney JV, Buckberg GD. Effects of pulsatile assistance and nonpulsatile flow on subendocardial perfusion during cardiopulmonary bypass. Ann Thorac Surg 1978;26:133-41.

4. Habal SM, Weiss MB, Spotnitz HM, et al. Effects of pulsatile and nonpulsatile coronary perfusion on performance of the canine left ventricle. J THORAC CARdiovasC SuRg 1976;72:742-5.

5. Schaff HV, Ciardullo RC, Flaherty JT, Brawley RK, Gott VL. Regional ischemia distal to a critical coronary stenosis during prolonged fibrillation: improvement with pulsatile perfusion. Circulation 1977; 56(Suppl):125-32.

6. Bixler TJ, Magee PG, Flaherty JT, Gardner TJ, Gott VL. Beneficial effects of pulsatile perfusion in the hypertrophied ventricle during ventricular fibrillation. Circulation 1979;60(Suppl):I141-6.

7. Dunn J, Peterson A, Kirsch MM. Effects of pulsatile perfusion upon left ventricular function. J Surg Res 1978;25:211-6.

8. Mori F, Ivey TD, Itoh T, Thomas R, Breazeale DG, Misbach G. Effects of pulsatile reperfusion on postischemic recovery of myocardial function after global hypothermic cardiac arrest. J THORAC CARDIOvasC SURG 1987;93:719-27.

9. Minami K, Korner MM, Vyska K, Kleesiek K, Knobl H, Korfer R. Effects of pulsatile perfusion on plasma catecholamine levels and hemodynamics during and after cardiac operations with cardiopulmonary bypass. J Thorac CARDIOVASC SURG 1990;99:82-91.

10. Philbin DM, Levine FH, Kono K, et al. Attenuation of the stress response to cardiopulmonary bypass by the addition of pulsatile flow. Circulation 1981;64:808-12.

11. Canivet JL, Larbuisson R, Damas P, et al. Plasma renin activity and urine $\beta 2$-microglobulin during and after cardiopulmonary bypass: pulsatile vs non-pulsatile perfusion. Eur Heart J 1990;11:1079-82. 
12. Nagaoka $H$, Innami $R$, Arai $H$. Effects of pulsatile cardiopulmonary bypass on the renin-angiotensinaldosterone system following open heart surgery. Jpn J Surg 1988;18:390-6.

13. Dapper F, Neppl H, Wozniak G, et al. Effects of pulsatile and nonpulsatile perfusion mode during extracorporeal circulation-a comparative clinical study. Thorac Cardiovasc Surg 1992;40:345-51.

14. Taylor KM, Wright GS, Bain WH, Caves PK, Beastall GS. Comparative studies of pulsatile and nonpulsatile flow during cardiopulmonary bypass. III. Response of the anterior pituitary gland to thyrotropin-releasing hormone. J ThORAC CARDIOVASC SURG 1978;75:57984.

15. Komoda T, Maeta H, Imawaki S, Shiraishi Y, Tanaka S. Hematologic and endocrinologic effects of pulsatile cardiopulmonary bypass using centrifugal pump. J Jpn Orthodont Soc 1992;40:901-11.

16. Maddoux G, Pappas G, Jenkins M, et al. Effect of pulsatile and nonpulsatile flow during cardiopulmonary bypass on left ventricular ejection fraction early after aortocoronary bypass surgery. Am J Cardiol 1976;37:1000-6.

17. Bregman D, Bowman FO, Parodi E, et al. An improved method of myocardial protection with pulsation during cardiopulmonary bypass. Circulation 1977;56:157-60.

18. Taylor KM, Bain WH, Davidson KG, Turner MA. Comparative clinical study of pulsatile and non-pulsatile perfusion in 350 consecutive patients. Thorax 1982;37:324-30.

19. Minami $\mathbb{K}$, Dramburg $\mathrm{W}$, Notohamiprodjo $\mathrm{G}$, Korfer R. Effects of pulsatile perfusion on perioperative morbidity and mortality in high-risk patients. In: Minami K, Korfer R, Wada J, eds. Cardio-thoracic surgery. What is new in current practice. Amsterdam: Elsevier, 1992:67-75.

20. Alston RP, Murray L, McLaren AD. Changes in hemodynamic variables during hypothermic cardiopulmonary bypass: effects of flow rate, flow character, and arterial pH. J Thorac Cardiovasc Surg 1990; 100:134-44.

21. Singh RKK, Barratt-Boyes BGF, Harris EA. Does pulsatile flow improve perfusion during hypothermic cardiopulmonary bypass? J Thorac CARdiovasc SURG 1980;79:827-32.

22. Louagie YA, Gonzalez M, Collard E, et al. Does flow character of cardiopulmonary bypass make a difference? J Thorac Cardiovasc Surg 1992;104:162838.

23. Alston RP, Singh M, McLaren AD. Systemic oxygen uptake during hypothermic cardiopulmonary bypass: effects of flow rate, flow character, and arterial pH. J Thorac Cardiovasc Surg 1989;98:757-68.
24. Kaul TK, Swaminathan R, Chatrath RR, Watson DA. Vasoactive pressure hormones during and after cardiopulmonary bypass. Int J Artif Organs 1990;13: 293-9.

25. Goto M, Kudoh K, Minami S, et al. The reninangiotensin-aldosterone system and hematologic changes during pulsatile and nonpulsatile cardiopulmonary bypass. Artif Organs 1993;17:318-22.

26. Levine FH, Phillips HR, Carter JE, et al. The effect of pulsatile perfusion on preservation of left ventricular function after aortocoronary bypass grafting. Circulation 1981;64(Suppl):II40-4.

27. Becker H, Vinten-Johansen J, Buckberg GD, et al. Myocardial damage caused by keeping $\mathrm{pH} 7.40$ during systemic deep hypothermia. J THORAC CARDIOvaSC Surg 1981;82:810-20.

28. Swain JA, White FN, Peters RM. The effect of $\mathrm{pH}$ on the hypothermic ventricular fibrillation threshold. J Thorac Cardovasc Surg 1984;87:445-51.

29. Swan $H$. The importance of acid-base management for cardiac and cerebral preservation during open-heart operations. Surg Gynecol Obstet 1984;158:391-414.

30. McConnell DH, White F, Nelson RL, et al. Importance of alkalosis in maintenance of "ideal" blood $\mathrm{pH}$ during hypothermia. Surg Forum 1975;26:263-5.

31. Hering JP, Schroder T, Singer D, Hellige G. Influence of $\mathrm{pH}$ management on hemodynamics and metabolism in moderate hypothermia. J THORAC CARDIOVASC SURG 1992;104:1388-95.

32. Sinet M, Muffat-Joly M, Bendaace T, Pocidalo J-J. Maintaining blood $\mathrm{pH}$ at 7.4 during hypothermia has no significant effect on work of the isolated rat heart. Anesthesiology 1985;62:582-7.

33. Murkin JM, Martzke JS, Buchan AM, Bentley C, Wong CJ. A randomized study of the influence of perfusion technique and $\mathrm{pH}$ management strategy in 316 patients undergoing coronary artery bypass surgery. II. Neurologic and cognitive outcomes. J THORaC Cardiovasc Surg 1995;110:349-62.

34. Badner NA, Murkin JM, Lok P. Differences in $\mathrm{pH}$ management and pulsatile/nonpulsatile perfusion during CPB do not influence renal function. Anesth Analg 1992;75:696-701.

35. Jones EL, Weintraub WS, Craver JM, Guyton RA, Cohen CL. Coronary bypass surgery: Is the operation different today? J THORAC CARDIOVASC SuRG 1991; 101:108-15.

36. Moores WY, Hannon JP, Crum JD, Willford DS. Continuous and pulsatile extracorporeal perfusion in the beating and fibrillating swine myocardium: effects on left ventricular function. Surg Forum 1977;28:262-4.

37. Bixler TJ, Magee PG, Flaherty JT, Gardner TJ, Gott VL. Beneficial effects of pulsatile perfusion in the 
hypertrophied ventricle during ventricular fibrillation. Circulation 1979;60:141-6.

38. Ciardullo RC, Schaff HV, Flaherty JT, Donahoo JS, Gott VL. Comparison of regional myocardial blood flow and metabolism distal to a critical coronary stenosis in the fibrillating heart during alternate periods of pulsatile and nonpulsatile perfusion. J THORAC Cardiovasc Surg 1978;75:193-205.

39. Ishikura $Y$, Tokunaga H, Shimazu A, et al. Clinical evaluation of pulsatile perfusion for long cardiopulmonary bypass. Kyobu Gek 1987;40:311-5.

40. Ide $\mathrm{H}$, Yamaguchi $\mathrm{A}$, Ino $\mathrm{T}$, et al. Evaluation of the pulsatility of a new pulsatile left ventricular assist device-the integrated cardioassist catheter-in dogs. J Thorac Cardiovasc Surg 1994; 107:569-75.

41. Watkins WD, Peterson MB, Kong DL, et al. Thromboxane and prostacyclin changes during cardiopulmonary bypass with and without pulsatile flow. J THORAC Cardiovasc Surg 1982;84:250-6.

42. Chitwood WR Jr, Sink JD, Hill RC, Wechsler AS. The comparative effects of pulsatile and non-pulsatile myocardial perfusion during cardiopulmonary bypass. J Surg Res 1981;30:553-62.

\section{ON THE MOVE?}

Don't miss a single issue of the journal! To ensure prompt service when you change your address, please photocopy and complete the form below.

Please send your change of address notification at least six weeks before your move to ensure continued service. We regret we cannot guarantee replacement of issues missed due to late notification.

\section{JOURNAL TITLE:}

Fill in the title of the journal here.

\section{OLD ADDRESS:}

Affix the address label from a recent issue of the journal here.

\section{NEW ADDRESS:}

Clearly print your new address here.

Name

Address

City/State/ZIP
COPY AND MAIL THIS FORM TO:

Journal Subscription Services

Mosby-Year Book, Inc.

11830 Westline Industrial Dr.

St. Louis, MO 63146-3318
OR FAX TO:

314-432-1158

N/ Mosby
OR PHONE:

1-800-453-4351

Outside the U.S., call

314-453-4351 